\title{
GANGLION CELL ACUITY IN HOODED RATS
}

\author{
LYNNe J. Friedman and Daniel G. Green \\ Vision Research Laboratory, Neuroscience Building, University of Michigan, Ann Arbor, MI 48109, U.S.A.
}

(Received 21 January 1981 ; in revised form 18 September 1981)

\begin{abstract}
Abatract-Previous measurements of retinal ganglion cell acuity in hooded rats have differed significantly from behavioral tests of visual acuity. One possible source of this discrepancy is examined-that light deprivation in early life may result in deficits in ganglion cell acuity. No evidence to support this hypothesis is found. Rat retinal ganglion cells exhibit a broad range of acuities. Cells with the highest resolving capacities have acuities close to those measured previously in behavioral tests. The relationships which may potentially exist between physiological and behavioral measures of visual acuity are discussed.
\end{abstract}

\section{INTRODUCTION}

During the past half century several investigators have made assessments of visual acuity in the pigmented rat. Typically, these studies have involved behavioral tests of acuity. The most recent behavioral tests have shown the maximum resolution of the pigmented rat to be $1.2 \mathrm{c} / \mathrm{deg}$ (Birch and Jacobs, 1979b). In these experiments, rats were required to discriminate gratings from homogeneous fields of the same average luminance. Previous estimates of visual acuity in the behaving rat have ranged from $0.5 \mathrm{c} / \mathrm{deg}$ (Lashley, 1930; Wiesenfeld and Branchek, 1976) to $1.0 \mathrm{c} / \mathrm{deg}$ (Hermann, 1958; Lashley, 1938).

Recently, electrophysiological techniques have been used in one study to measure visual acuity of single retinal ganglion cells. The highest spatial frequency grating detectable by single units was found to range from 0.09 to $0.40 \mathrm{c} / \mathrm{deg}$. The average acuity for all cells tested was $0.22 \mathrm{c} / \mathrm{deg}$ (Powers and Green, 1978).

The discrepancy between previous electrophysiological determinations of ganglion cell acuity and the most recent behavioral acuity measurements is approximately three-fold. The obvious dilemma is how a behaving rat can apparently see spatial frequencies which do not seem to be detected at the retinal ganglion cell level. An equally important question to ask is whether one should, in fact, expect agreement between visual acuity measured in the behaving animal and the acuities of retinal ganglion cells. This issue is addressed in the discussion section.

Before proceeding further, let us clarify what we mean by the "acuity" of a ganglion cell. Visual acuity, as usually defined, is a psychological measure of the resolving capabilities of a visual system. The measurements reported in this study are of physiological responses. When a ganglion cell detects a moving grating, its discharge is modulated as light and dark bars cross its receptive field. The threshold for this response is measured, and the cell is said to display a certain level of visual acuity. What we mean is that if the animal were able to utilize only the information being relayed by this one cell, then it is assumed that this would define the level of visual acuity in his perceptual world.

In order to explore the relationship between these two different measures of visual acuity, some methodological differences between the most recent behavioral study, and the prior electrophysiological report needed to be reconciled. Both studies reported that the luminance level of their test gratings did not effect acuity. However, most of the gratings used in the behavioral tests were at higher luminance than those used in the electrophysiological experiments.

One other variable was confounded in these experiments. The lighting conditions in the early visual environment of the animals used in the two studies were different. The lower acuities, determined electrophysiologically, were for rats deprived of light from birth (Powers and Green, 1978). The higher behavioral acuities were obtained from rats raised in cyclic light (12 hr light/12 hr darkness) (Birch and Jacobs, 1979b). A rat that is born and reared in total darkness might suffer a deficit in visual acuity and this deficit might be apparent at the level of the ganglion cells.

There is some indication that rats reared in darkness have higher absolute sensitivities to light than rats which have been exposed to light (Birch and Jacobs, 1979a). Prolonged stay in the dark could produce substantial improvements in the sensitivity of the rod photoreceptors themselves or alternatively, dark-rearing could produce some sort of neural reorganization-so that more rods pool their signals into each ganglion cell. The latter would result in enlarged ganglion cell receptive fields. The cost of having unusually high sensitivities to light might be poorer acuity than normal.

This study examines the effects of light vs darkrearing on the spatial resolving power of the rat retinal ganglion cell.

\section{METHODS}

Electrophysiological recordings of retinal ganglion 
cells were obtained from two groups of Long-Evans hooded rats. One group (dark-reared) consisted of animals born and raised in the dark, except for brief exposures to dim red illumination. The second group of animals (light-reared) was raised on a schedule of cyclic light $-12 \mathrm{hr}$ of normal room illumination followed by $12 \mathrm{hr}$ of darkness.

Recordings were obtained when the rats were between 1.5 and 2.5 months of age $(216-465 \mathrm{~g}$ of weight). A total of nine rats were examined - 4 darkreared and 5 light-reared. Potential experimenter biases were eliminated. On the testing days, an assistant randomly chose an animal from one of the rearing groups and brought it to the experimenters. Not until the end of the last recording session were the experimenters told from which of the rearing groups each rat had come.

A rat was anesthetized with intraperitoneal injections of urethane. Insertion of a tracheal cannula allowed for artificial respiration. A cannula was also placed in the femoral vein, through which a solution containing gallimine triethiodide (Flaxedil), tuborcurarine chloride, urethane and dextrose in saline was continuously infused. This solution served to paralyze the animal, maintain anesthesia and supply nutrition during the experiment.

The animal was placed in a stereotaxic apparatus, and the skull was opened. A plano contact lens was placed over the eye in order to keep the cornea moist. In order to locate the optic tract, electrodes recording massed responses (glass micropipettes filled with cerrolow metal) were lowered into the brain, and diffuse light flashes were delivered to the eye. Once the tract was located, tungsten in glass microelectrodes (Levick, 1972) were used to record from single optic tract units.

When a single unit was isolated, its receptive field was located in space on a tangent screen placed $30-40 \mathrm{~cm}$ away from the eye. Square-wave gratings of various spatial frequency were projected onto the screen, and moved across the entire receptive field. The finest grating to which the unit responded was determined by auditory criteria. The luminance of the grating pattern was varied and its effect on acuity was noted. An attempt was made to find the optimum luminance level for each cell's performance. If a change in luminance level was found to improve acuity, the new, increased value was defined as the maximal resolution for the unit. Similarly, the drift rate of the grating across the receptive field was varied until it seemed that the optimum rate had been found.

\section{RESULTS}

Acuity measurements were obtained for a total of 85 retinal ganglion cells. The histograms in Fig. 1 represent the distributions of these measurements for dark-reared (Fig. 1a, $N=43$ cells) and light-reared (Fig. 1b, $N=42$ cells) rats. The average acuity of

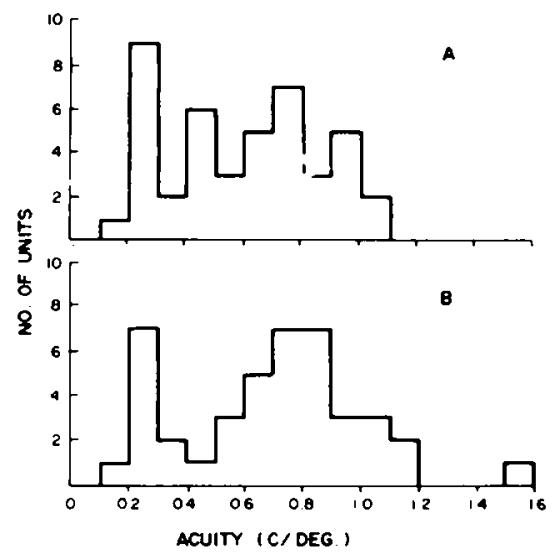

Fig. 1. Distribution of visual acuities determined for retinal ganglion cells: (A) Dark-reared rats. average $=0.575 \mathrm{c} / \mathrm{deg}$. $N=43$ units from 4 animals. (B) Light-reared rats, average $=0.685 \mathrm{c} / \mathrm{deg}, N=42$ units from 5 animals. No significant difference exists.

single units from dark-reared animals is $0.575 \mathrm{c} / \mathrm{deg}$. with a standard deviation of 0.269 . For light-reared animals average acuity is $0.685 \mathrm{c} / \mathrm{deg}$, with a standard deviation of 0.269 . No difference between the average acuity of cells examined in dark- vs light-reared animals is apparent.

In addition, comparing Figs $1 \mathrm{a}$ and $1 \mathrm{~b}$ by eye, the distributions of acuities for single units from darkand light-reared rats seem to be essentially the same. Ganglion cells from both groups exhibit a broad range of acuities. The variance within each rearing group is not a function of difference between animals. Rather, units from individual animals show large variability in resolving capacity. Table 1 illustrates this point by listing the means and standard deviations of acuity measurements for units from individual rats.

In Fig. 2, data from both rearing groups have been pooled, and overall distribution of acuities measured for all units is displayed (composite of Figs $1 \mathrm{a}$ and $\mathrm{lb}$; total $N=85$ cells). The resulting overall mean acuity is $0.629 \mathrm{c} / \mathrm{deg}$, with a SD of 0.293 . The frequency distribution in Fig. 2 is approximately bimodal (as indi-

Table 1. Average acuities for individual rats

\begin{tabular}{ccccc}
\hline Date & $\begin{array}{c}\text { Rearing } \\
\text { condition }\end{array}$ & $\begin{array}{c}\text { Average } \\
\text { acuity } \\
\text { (c/deg) }\end{array}$ & $\begin{array}{c}\text { Standard } \\
\text { deviation }\end{array}$ & $\begin{array}{c}\text { No. of } \\
\text { units }\end{array}$ \\
\hline $6 / 19 / 79$ & Dark & 0.370 & 0.164 & 5 \\
$6 / 19 / 79$ & Dark & 0.694 & 0.312 & 14 \\
$6 / 29 / 79$ & Light & 0.770 & 0.338 & 15 \\
$7 / 02 / 79$ & Dark & 0.556 & 0.240 & 20 \\
$7 / 06 / 79$ & Light & 0.720 & 0.098 & 4 \\
$7 / 10 / 79$ & Dark & 0.515 & 0.212 & 4 \\
$7 / 16 / 79$ & Light & 0.597 & 0.246 & 6 \\
$7 / 30 / 79$ & Light & 0.482 & 0.307 & 9 \\
$7 / 31 / 79$ & Light & 0.802 & 0.295 & 8 \\
\hline
\end{tabular}




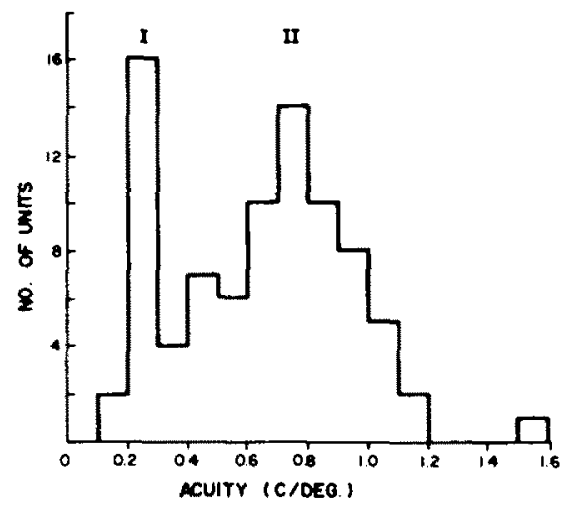

Fig. 2. Overall Acuity distribution for all 85 units. Data from Fig. IA and B have been combined. The two peaks in the bimodel distribution ate labelled $I$ and II.

cated roughly by regions labelled I and II, low and high acuity units, respectively). While this division is somewhat arbitrary, oftentimes units from these two "classes" behaved quite differently to changes in the luminance of the grating stimuli. Units with low acuity (region I) were generally unaffected by changes in grating pattern luminance. For some of these units, increases in luminance acted to impair resolving capacity. In comparison, changes in luminance level frequently affected higher acuity units (those in region II). Many of these units were initially judged to have poor resolving capacities. With increases in grating luminance, however, they were found to improve to the higher acuity levels at which they now appear in these figures. The existence of these two distinct "classes" of optic tract units is suggested in both rearing groups. Examples of the two types of units are shown in Fig. 3.

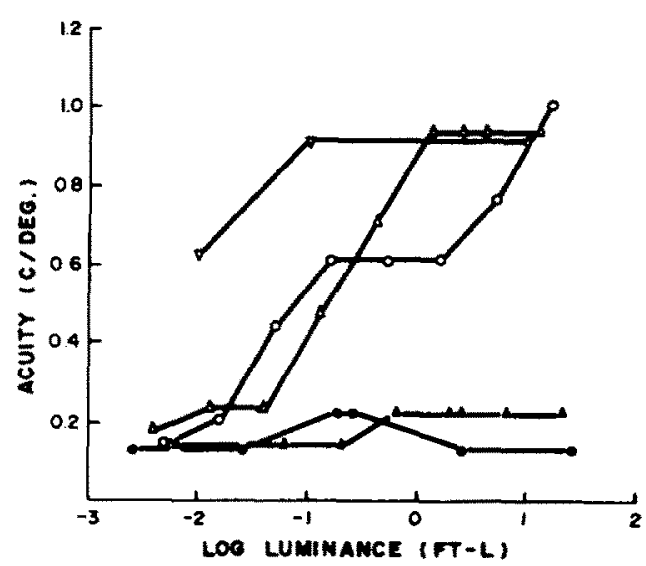

Fig. 3. Effect of luminance on ganglion cell high spatial frequency resolution. Units from region 1 of Fig. 2 are indicated with filled symbols (- off-unit from dark-reared rat. $\Delta$ - off-unit from light-reared rat) and units from region II are indicated with open symbols 10 - off-unit from darkreared rat. $\nabla$ - off-unit from dark-reared rat, $\Delta$ - on-unit from dark-reared rat)
The physiological basis for this distinction has not been investigated. It may be a consequence of different inputs (rod or cone) to the two cell types. Alternatively, since dark-adapted rat retinal ganglion cells do not exhibit a concentric surround antagonistic to the center (Green et al., 1977; Cicerone and Green, 1980) and some light-adapted cells do show this organization (Partridge and Brown, 1970), the influence of a receptive field surround mechanism may act to improve resolving capacity in the region II (high acuity) units.

\section{DISCUSSION}

A comparison was made between the visual acuities of retinal ganglion cells in light- and dark-reared rats. Ganglion cells from rats reared in these different lighting conditions were found to have comparable resolving capacities. Within a single animal, the optic tract contains cells with a broad range of acuities. We find no evidence that this range of visual acuities is affected by the lighting conditions in the rat's early environment.

In the introduction, the question was raised of whether one should expect agreement between acujties measured in retinal ganglion cells, and visual acuity measured in the behaving animal. In the simplest case imaginable, the behaving rat would exhibit a certain level of visual acuity, and every ganglion cell would display this same resolving capacity. The animal would gain no more information from all of its ganglion cells than we obtained recording from a single one. Logically, however, this simple correlation is not necessary. Various other physiological arrangements might produce the same level of visual acuity in the behaving rat. For example, ganglion cell responses may be compared more centrally in the visual system. The animal might utilize this processed signal for his perceptual experience. Given our methods, it is possible that any information carried by such a processed signal might not be apparent in the recording from individual ganglion cells.

Our results show that the relationship between physiology and behavior is not the simplest to imagine (that is, all ganglion cells having the same acuity as the behaving animal). Cells in the rat optic tract display a broad range of resolving capacities. The acuities measured previously in behaving rats are close to those which this study has found in the highest acuity fibers of the optic tract. It is certainly conceivable that these high acuity cells mediate detection when the animal engages in visual discrimination tasks which test for acuity. There is no need to postulate central processing of signals from many ganglion cells in order to explain the resolving capacity of the behaving animal.

In light of our results, some probable explanations for the lower electrophysiological acuities reported previously (Powers and Green, 1979) may be sug. gested. One examination of a smaller sample of 
ganglion cells might fail to reveal the wide diversity in their resolving capacities. In addition, we find luminance to have considerable effects on only some cells. If every cell is not examined at a large range of luminances, extreme underestimates of the visual acuity of optic tract fibers may result.

In the introduction, we hypothesized that visual acuity deficits might be suffered so that absolute sensitivities to light might increase. This hypothetical trade-off was examined further, by measuring absolute thresholds of retinal ganglion cells in two additional animals - one a dark-reared, the other a light-reared rat ( 7 and 6 units, respectively). No difference between the two was apparent. Although these samples were small, this lack of any difference in absolute sensitivity between a dark- and a light-reared rat is consistent with the negative findings for acuity reported in this study.

In conclusion, at the level of the optic tract, visual acuity in the pigmented rat is not affected by lighting conditions in the early environment. Visual acuity, as measured by the performance of a behaving rat, closely resembles the resolving capacity of the highest acuity fibers found in the optic tract.

Acknowledgements-This research was supported by NIH grant EY00379. L.J.F. was supported by EY07022 and an
NSF graduate fellowship. We thank Mathew Alpern for his helpful comments on an earlier version of the manuscript.

\section{REFERENCES}

Birch D. and Jacobs G. H. (1979a) Effects of prolonged dark exposure on visual thresholds. Invest. Ophthal. Visual Sci. 18, 752-756.

Birch D. and Jacobs G. H. (1979b) Spatial contrast sensitivity in albino and pigmented rats. Vision Res. 19, 933-937.

Cicerone C. M. and Green D. G. (1980) Light adaptation within the receptive field centre of rat retinal ganglion cells. J. Physiol. 301, 517-534.

Green D. G., Tong L. and Cicerone C. M. (1977) Lateral spread of light adaptation in the rat retina. Vision Res. $17,479-486$.

Hermann G. (1958) Beitrage zur Physiologie des Ratenauges. $Z$. Tierspsychol. 15, 462-518.

Lashley K. S. (1930) The mechanism of vision III: The comparative visual acuity of pigmented and albino rats. J. gen. Psychol. 37, 481-484.

Lashley K. S. (1938) The mechanism of vision XV: Preliminary studies of the rat's capacity for detailed vision. $J$. gen. Psychol. 18, 123-193.

Levick W. R. (1972) Another tungsten microelectrode. Med. Biol. Engng 10, 510-515.

Partridge L. D. and Brown J. E. (1970) Receptive fields of rat retinal ganglion cells. Vision Res. 10, 455-460.

Powers M. K. and Green D. G. (1978) Single retinal ganglion cell responses in the dark-reared rat: grating acuity, contrast sensitivity, and defocusing. Vision Res. 18 , 1533-1539.

Wiesenfeld Z. and Branchek T. (1976) Refractive state and visual acuity in the hooded rat. Vision Res. 16, 823-827. 